Article

\title{
Removal of Sulfadiazine Using 3D Interconnected Petal-Like Magnetic Reduced Graphene Oxide (MrGO) Nanocomposites
}

\author{
Jie Zhong ${ }^{1,2}$, Yong Feng ${ }^{1,2, *}$, Jin-Ling $\mathrm{Li}^{1,2}$, Bin Yang ${ }^{1,2}$ and Guang-Guo Ying ${ }^{1,2, *}$ \\ 1 SCNU Environmental Research Institute, Guangdong Provincial Key Laboratory of Chemical Pollution and \\ Environmental Safety \& MOE Key Laboratory of Theoretical Chemistry of Environment, \\ South China Normal University, Guangzhou 510006, China; Jie.zhong@m.scnu.edu.cn (J.Z.); \\ 13069312053@163.com (J.-L.L.); bin.yang@m.scnu.edu.cn (B.Y.) \\ 2 School of Environment, South China Normal University, University Town, Guangzhou 510006, China \\ * Correspondence: yong.feng@m.scnu.edu.cn (Y.F.); guangguo.ying@m.scnu.edu.cn (G.-G.Y.); \\ Tel.: +86-020-8472-1549 (Y.F.); +86-020-3931-0796 (G.-G.Y.)
}

Received: 1 June 2020; Accepted: 6 July 2020; Published: 7 July 2020

\begin{abstract}
Adsorption has been regarded as one of the most efficient and economic methods for the removal of antibiotics from aqueous solutions. In this work, different graphene-based magnetic nanocomposites using a modified solvothermal method were synthesized and employed to remove sulfadiazine (SDZ) from water. The adsorption capacity of the optimal magnetic reduced graphene oxide (MrGO) was approximately 3.24 times that of pure $\mathrm{Fe}_{3} \mathrm{O}_{4}$. After five repeated adsorption cycles, the removal rate of SDZ (100 $\mu \mathrm{g} / \mathrm{L})$ by MrGO nanocomposites was still around $89.3 \%$, which was only about a $3 \%$ decrease compared to that in the first cycle. Mechanism investigations showed that both chemical and physical adsorption contributed to the removal of SDZ. The excellent adsorption performance and recyclability of MrGO nanocomposites could be attributed to their wonderful 3D interconnected petal-like structures. The MrGO with SDZ could be easily recollected by magnetic separation. The MrGO also exhibited excellent adsorption performance in the purification of real polluted water.
\end{abstract}

Keywords: adsorption; sulfadiazine; magnetic reduced graphene oxide; nanocomposites

\section{Introduction}

Antibiotics, an important group of pharmaceuticals used in humans and animals, have caused significant concern in recent years due to their wide occurrence and resistance. Most antibiotics are partially metabolized in organisms and excreted to the environment through urine and feces in the form of their parent compounds or metabolites [1]. The concentration of some antibiotics has been measured to reach a ppm level in hospitals or sewage effluents [2]. Sulfadiazine (SDZ, the total usage was $1260 \mathrm{t} / \mathrm{yr}$ in 2013), the second most widely used pharmaceutical of 13 kinds of common sulfonamides in China [3], has been widely detected in different environments, such as wastewater treatment plants [4], hospitals [5], groundwater [6], and livestock farms [7]. Exposure to low concentrations of antibiotics, such as SDZ, could lead to the accumulation and spread of antibiotic resistance genes (ARGs) and antibiotic-resistant bacteria (ARB), which are expected to impact the ecosystem and human health $[1,2]$.

To remove antibiotics, large numbers of studies have been carried out to develop treatment technologies. Among the technologies investigated, adsorption is regarded as one of the most efficient and economic approaches for the removal of antibiotics from aqueous solutions $[8,9]$. Mesoporous materials are used as adsorbents because of their high surface area and versatile surface functional groups, which have attracted increasing attention $[10,11]$. Reduced graphene oxide (rGO), 
a derivative of graphene, shows great promise as an effective adsorbent because of its large specific surface area and abundant pore structures [12,13]. During the past few years, many studies have been carried out to investigate the removal of heavy metal ions and dyes using rGO and very promising results have been achieved. Some reports show that the maximum adsorption capacities for methylene blue and $\mathrm{Pb}^{2+}$ could reach to 433 and $416 \mathrm{mg} / \mathrm{g}$ [14,15], respectively. However, few investigations on the interaction between antibiotic contaminants and graphene-based materials have been conducted. The structure of different kinds of antibiotics may vary greatly, and different driving forces are generated in the adsorption process. Some zwitterionic antibiotics carry cations or anions and are readily adsorbed by anionic or cationic adsorbents. Some antibiotics are rich in aromatic ring structures, producing $\pi-\pi$ electron in the forms of a donor-acceptor with rGO $[16,17]$. SDZ is used in large quantities and contains an aromatic ring in its structure. Therefore, it is of great significance to study the adsorption process of SDZ on graphene-based materials.

Due to the van der Waals force and $\pi-\pi$ interactions between layers [18], free-standing rGO nanosheets are easy to stack and agglomerate, which decreases the specific surface area and adsorption capacity. It is difficult for pollutants to acquire paths into the inner layers of the stacked graphene. To retain the inherent property of graphene, three-dimensional (3D) graphene was constructed [19,20]. Although this kind of structure improved the performance of graphene to some extent, the separation and recycle of rGO emerges to be another important issue. Recently, magnetization-introduced $\mathrm{Fe}_{3} \mathrm{O}_{4}$ nanoparticles have been focused and developed benefiting from the rapid and facile separation using a magnet [21,22]. However, although magnetic $\mathrm{Fe}_{3} \mathrm{O}_{4}$ nanoparticles have good biocompatibility and stability, their weak adsorption capacity is an issue. As a result, it is urgent to fabricate rGO-integrated magnetic $\mathrm{Fe}_{3} \mathrm{O}_{4}$ nanocomposites with 3D interconnected porous structures.

Herein, we prepared a series of magnetic material using a modified solvothermal method. Materials were synthesized via the reduction of $\mathrm{FeCl}_{3}$ using an ethylene glycol solvent with sodium acetate as an electrostatic stabilizer and alkali source. By controlling the content of rGO, the MrGO magnetic nanocomposites with different porous structures were synthesized. To evaluate the adsorption performance, SDZ was selected as the target contaminant. Batch experiments and different analysis methods were carried out. The results from this work could help find an effective method to obtain magnetic nanocomposites with porous structures, avoiding the stacking and aggregation of rGO nanosheets.

\section{Materials and Methods}

\subsection{Chemicals and Materials}

Flake graphite, ferric chloride hexahydrate $\left(\mathrm{FeCl}_{3} \cdot 6 \mathrm{H}_{2} \mathrm{O}\right)$, sodium acetate $\left(\mathrm{CH}_{3} \mathrm{COONa}\right)$, and ethylene glycol (EG) were purchased from Guangzhou Chemical Regent Company (Guangzhou, China). SDZ (purity 99.1\%) was purchased from Dr. Ehrenstorfer GmbH (Augsburg, Germany). All chemicals used in this study were of analytical grade. Ultrapure water $(\geq 18 \mathrm{M} \Omega \mathrm{cm})$ was used to prepare experimental solutions throughout this study.

\subsection{Preparation of $M r G O$}

Graphene oxide (GO) was prepared using natural flake graphite with a modified Hummer method. The details can be found in our previous work [23]. For the preparation of $\mathrm{MrGO}, 1.05 \mathrm{~g} \mathrm{FeCl}_{3} \cdot 6 \mathrm{H}_{2} \mathrm{O}$ and $1.8 \mathrm{~g} \mathrm{CH}_{3} \mathrm{COONa}$ were dissolved in a $100-\mathrm{mL}$ EG solution. Then, $0.1 \mathrm{~g} \mathrm{GO}$ was added and the resulting suspension was stripped by ultrasonic treatment for $2 \mathrm{~h}$ to obtain a homogeneous colloidal solution. The solution was stirred continually for $1 \mathrm{~h}$. Next, $50 \mathrm{~mL}$ of the colloidal solution was transferred into a teflon-lined stainless steel autoclave $(100 \mathrm{~mL})$ and heated at $200{ }^{\circ} \mathrm{C}$ for $10 \mathrm{~h}$. When the autoclave naturally cooled to the room temperature, the magnetic nanocomposite was prepared. The nanocomposite was washed several times with deionized water, recollected magnetically, and freeze-dried for $12 \mathrm{~h}$. The resulting magnetic nanocomposite was named as MrGO-1. 
A pure $\mathrm{Fe}_{3} \mathrm{O}_{4}$ sample, used as a benchmark, was prepared using the same procedure as described above, except that no GO was added. Similarly, MrGO-2 (0.2 g GO) and MrGO-3 (0.3 g GO) were prepared by controlling the amount of GO. Moreover, $\mathrm{rGO}$ was synthesized using the same approach as stated above. The schematic illustration of preparing the MrGO nanocomposites is shown in Figure 1.

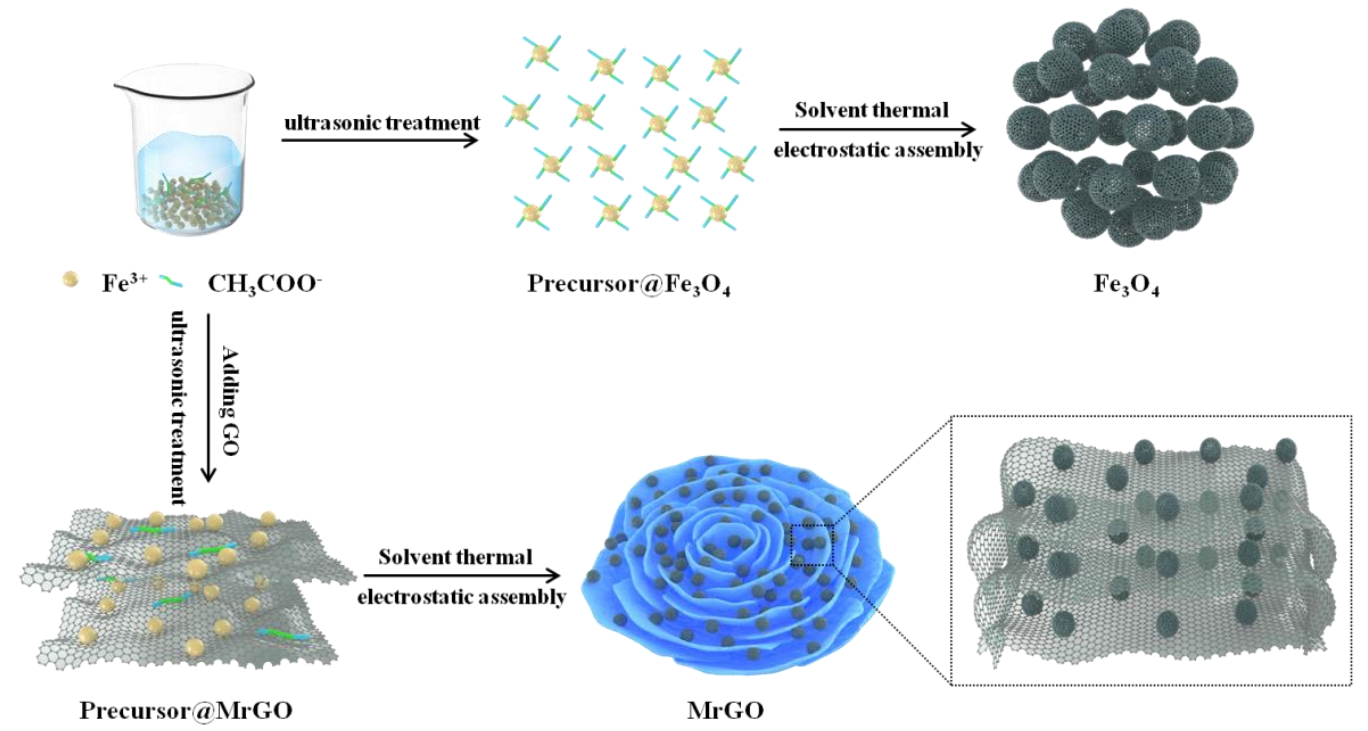

Figure 1. Schematic illustration of preparing the MrGO nanocomposite.

\subsection{Material Characterizations}

Powder X-ray diffraction (XRD, D/MAX 2200 VPC, Rigaku, Japan) was used to characterize the crystalline structures with $\mathrm{Cu} \mathrm{K} \alpha(\lambda=1.5406 \AA)$ radiation at a scan step of $0.2 \mathrm{~s}^{-1}$ from $5^{\circ}$ to $80^{\circ}$. Fourier transform infrared spectroscopy (FT-IR, Spectrum two, Perkin-Elmer, Waltham, MA, USA) was used to study the functional groups on the material surfaces. The magnetic properties (VSM) were investigated using a superconducting quantum interference device (SQUID) magnetometer (MPMS3). Thermo gravimetric analysis (TGA, STA409PC, Netzsch, Germany) was used to confirm the content of the composite under air in the temperature range of $30-800^{\circ} \mathrm{C}$. The Brunauer-Emmett-Teller (BET, ASAP-2020, Micromeritics, Norcross, GA, USA) was conducted to measure the specific surface area and pore size distribution under $\mathrm{N}_{2}$ adsorption/desorption. The particle size properties were measured using a particle size analyzer (Zetasizer Nano ZS90, Malvern, England). X-ray photoelectron spectroscopy (XPS, ESCALab250, ThermoFisher, Dreieich, Germany) was applied to determine the surface chemical compositions and electronic structures. The morphologies and microstructures were observed using a scanning electron microscope (SEM, ZEISS Ultra-55, Oberkochen, Germany) and a transmission electron microscope (TEM, JEM-1600HR, JEOL, Toyko, Japan).

\subsection{Adsorption and Recyclability Experiments}

To study the adsorption kinetics of SDZ, batch experiments were conducted. A standard SDZ solution with a concentration of $400 \mu \mathrm{g} / \mathrm{L}$ was prepared in advance. Then, five types of the as-prepared absorbents $(5 \mathrm{mg})$ were added respectively into centrifuge tubes $(50 \mathrm{~mL})$ containing the SDZ standard aqueous solution $(20 \mathrm{~mL}$ ). The samples were stirred in a rotating shaker (WSZ-100A, Shanghai Yiheng, Shanghai, China) with a speed of $180 \mathrm{rpm}$ at $25^{\circ} \mathrm{C}$. The solution $\mathrm{pH}$ was not controlled because no obvious variation $(<0.2)$ occurred after the adsorption. At the preselected adsorption time $(0.5-24 \mathrm{~h})$, a series of samples $(1 \mathrm{~mL})$ were withdrawn with syringes and filtered through $0.22-\mu \mathrm{m}$ PES filter membranes (The recovery was about $98.5 \%$ ). The residual concentrations of SDZ were measured using LC-MS. Control experiments were also conducted simultaneously through the same procedures without adding an adsorbent. The adsorption isotherms were studied with a series of different initial 
concentrations of SDZ (50-2000 $\mu \mathrm{g} / \mathrm{L}$ ) using the same procedure stated above and the adsorption time was fixed at $3 \mathrm{~h}$. All the batch adsorption experiments were performed in duplicate.

The recyclability experiments were conducted as follows. A standard SDZ solution with a concentration of $100 \mu \mathrm{g} / \mathrm{L}$ was prepared. Next, $5 \mathrm{mg}$ of the as-prepared adsorbent was added, and adsorption reactions were performed with the same procedures as mentioned above, but the adsorption time was changed to $3 \mathrm{~h}$. After the supernatant was quickly separated by a magnet, the precipitates were recollected and re-dispersed in a $20 \mathrm{~mL} \mathrm{NaOH}$ solution $(0.1 \mathrm{M})$ for the desorption of SDZ. The experimental parameters of the desorption process were in accord with those of the adsorption. Next, the recollected adsorbent was washed with deionized water until the $\mathrm{pH}$ value reached to near 7 . After that, the adsorbent was reused for SDZ adsorption. These procedures were repeated five times.

Different water samples were collected to evaluate the practical application potential of the adsorbents. Lake water (LW), river water (RW), and waste water (WW) were collected from the Liuxi Lake, East River, and the effluent of Guangzhou Liede Waste Water Treatment Plant, respectively, which are all located in the Pearl River Basin, Guangdong, China. The water samples were filtered through $0.45-\mu \mathrm{m}$ PES filter membranes within $24 \mathrm{~h}$ and then stored at $4{ }^{\circ} \mathrm{C}$ until use. These real water samples were characterized, and the results are shown in Table 1.

Table 1. Properties of real water samples.

\begin{tabular}{cccc}
\hline Parameters & LW & RW & WW \\
\hline pH & 7.5 & 7.4 & 7.2 \\
Conductivity $(\mu \mathrm{S} / \mathrm{cm})$ & 83.1 & 114.3 & 471.2 \\
UV $_{400}$ & 0.08 & 0.09 & 0.1 \\
$\mathrm{TOC}(\mathrm{mg} / \mathrm{L})$ & 2.3 & 2.5 & 6.7 \\
$\mathrm{IC}(\mathrm{mg} / \mathrm{L})$ & 2.8 & 3.7 & 10.8 \\
$\mathrm{Cu}(\mathrm{mg} / \mathrm{L})$ & 0.012 & 0.012 & 0.013 \\
$\mathrm{Fe}(\mathrm{mg} / \mathrm{L})$ & 0.0020 & 0.017 & 0.011 \\
$\mathrm{Mn}(\mathrm{mg} / \mathrm{L})$ & 0.02 & 0.01 & 0.31 \\
$\mathrm{Cl}(\mathrm{mg} / \mathrm{L})$ & 1.46 & 4.14 & 41.00 \\
$\mathrm{~S}(\mathrm{mg} / \mathrm{L})$ & 0.92 & 2.22 & 14.48 \\
\hline
\end{tabular}

LW: lake water; RW: river water; WW: waste water.

The adsorption capacity $\left(Q_{t}, \mu g / m g\right.$, Equation (1)) of adsorbent and removal efficiency ( $w, \%$, Equation (2)) of SDZ were calculated as follows:

$$
\begin{gathered}
\mathrm{Q}_{\mathrm{t}}=\frac{\left(\mathrm{C}_{0}-\mathrm{C}_{\mathrm{e}}\right) \times \mathrm{V}}{\mathrm{m}} \\
\mathrm{w}=\frac{\left(\mathrm{C}_{0}-\mathrm{C}_{\mathrm{e}}\right)}{\mathrm{C}_{0}} \times 100 \%
\end{gathered}
$$

where $C_{0}$ and $C_{e}(\mu \mathrm{g} / \mathrm{L})$ are the initial and equilibrium concentrations of SDZ, respectively, $\mathrm{m}(\mathrm{mg})$ is the mass of the adsorbent, and V (L) is the volume of SDZ solution.

The pseudo-first-order model (Equation (3)) and pseudo-second-order model (Equation (4)) were used to investigate the adsorption kinetic:

$$
\begin{gathered}
\mathrm{Q}_{\mathrm{t}}=\mathrm{Q}_{\mathrm{e}} \times\left(1-\mathrm{e}^{-\mathrm{k}_{1} \mathrm{t}}\right) \\
\frac{\mathrm{t}}{\mathrm{Q}_{\mathrm{t}}}=\frac{1}{\mathrm{Q}_{\mathrm{e}}} \mathrm{t}+\frac{1}{\mathrm{k}_{2} \mathrm{Q}_{\mathrm{e}}{ }^{2}}
\end{gathered}
$$

If $Q_{e}$ is measured in the experiments, the fractional uptake $(F)$ with respect to the equilibrium can be calculated via Equation (5):

$$
\mathrm{F}(\mathrm{t})=\mathrm{Q}_{\mathrm{t}} / \mathrm{Q}_{\mathrm{e}}
$$


Substituting Equation (3) into Equation (5) yielded:

$$
F(t)=1-e^{-k_{1} t}
$$

When Equation (4) was substituted into Equation (5), the fractional uptake could be expressed:

$$
\mathrm{F}(\mathrm{t})=\frac{\mathrm{k}_{2}{ }^{*} \mathrm{t}}{1+\mathrm{k}_{2}{ }^{*} \mathrm{t}}\left(\mathrm{k}_{2}^{*}=\mathrm{k}_{2} \mathrm{Q}_{\mathrm{e}}\right)
$$

where $Q_{e}(\mu g / m g)$ is the adsorption capacity at the equilibrium state, $t(h)$ is the predetermined time, $\mathrm{k}_{1}\left(\mathrm{~h}^{-1}\right)$ is the pseudo-first-order adsorption rate constant, and $\mathrm{k}_{2}(\mathrm{mg} /(\mu \mathrm{g} \cdot \mathrm{h}))$ is the pseudo-second-order adsorption rate constant.

The Langmuir (Equation (8)) and Freundlich (Equation (9)) models were used to analyze the adsorption isotherm data:

$$
\begin{gathered}
\frac{\mathrm{C}_{\mathrm{e}}}{\mathrm{Q}_{\mathrm{e}}}=\frac{1}{\mathrm{~K}_{\mathrm{L}} \mathrm{Q}_{\mathrm{m}}}+\frac{\mathrm{C}_{\mathrm{e}}}{\mathrm{Q}_{\mathrm{m}}} \\
\mathrm{Q}_{\mathrm{e}}=\mathrm{K}_{\mathrm{F}} \mathrm{C}_{\mathrm{e}}^{1 / \mathrm{n}}
\end{gathered}
$$

where $\mathrm{K}_{\mathrm{L}}(\mathrm{L} / \mu \mathrm{g})$ is the Langmuir isotherm constant, $\mathrm{Q}_{\mathrm{m}}(\mu \mathrm{g} / \mathrm{mg})$ is the maximum adsorption capacity, $\mathrm{K}_{\mathrm{F}}\left(\mu \mathrm{g} / \mathrm{mg}(\mathrm{L} / \mu \mathrm{g})^{1 / \mathrm{n}}\right)$ is the Freundlich isotherm constant, and $\mathrm{n}$ is the measure of adsorption intensity.

\subsection{Chemical Analysis}

The concentration of SDZ in the residual solution was analyzed using an ACQUITY UPLC-Xevo TQ MS system (Waters, Milford, MA, USA). The mobile phase consisted of methanol and ultrapure water $(0.1 \%$ formic acid) at a volume ratio of $60: 40$, and a BEH-C18 column $(1.7 \mu \mathrm{m}, 2.1 \mathrm{~mm} \times 100 \mathrm{~mm})$ was used for the separation. The flow rate was set at $0.3 \mathrm{~mL} / \mathrm{min}$ and the column temperature $40^{\circ} \mathrm{C}$. An injection volume of $10 \mu \mathrm{L}$ was used for all samples. Calibration curves were established using a series of standard SDZ solutions in the range of 10 to $400 \mu \mathrm{g} / \mathrm{L}$.

\section{Results and Discussion}

\subsection{Characterization}

The XRD spectra of $\mathrm{Fe}_{3} \mathrm{O}_{4}, \mathrm{MrGO}-1, \mathrm{MrGO}-2, \mathrm{MrGO}-3$, and rGO were shown in Figure 2a. In the spectrum of the $\mathrm{Fe}_{3} \mathrm{O}_{4}$ sample, diffraction peaks were observed at $2 \theta=18.3^{\circ}, 30.1^{\circ}, 35.5^{\circ}, 43.1^{\circ}, 53.5^{\circ}$, $57.0^{\circ}, 62.6^{\circ}$, and $75.1^{\circ}$, which can be indexed to the (111), (220), (311), (400), (422), (511), (440), and (662) planes of $\mathrm{Fe}_{3} \mathrm{O}_{4}$ (JCPDS No.75-0033), respectively. These diffraction peaks were also observed in the spectra of MrGO-1, MrGO-2, and MrGO-3. The peaks were sharp and intense, which demonstrates a well-crystallized form of magnetic materials. In the $2 \theta$ range of $20-25^{\circ}$, the rGO sample shows a broad diffraction peak, which corresponds to the (002) plane of rGO amorphous carbon [23]. As shown in the spectra of MrGO-1, MrGO-2, and MrGO-3 samples, the weak signals of rGO could also be tracked [24]. With increasing content of $\mathrm{rGO}$, the corresponding peaks of the nanocomposites became increasingly obvious. These results reveal that the $\mathrm{Fe}_{3} \mathrm{O}_{4}$ nanoparticles in the MrGO nanocomposites were successfully deposited onto the rGO nanosheet. The FTIR spectra data are shown in Figure $2 \mathrm{~b}$. The characteristic band near $600 \mathrm{~cm}^{-1}$ is intense, owing to the bending vibration of the Fe-O bonds [25]. Meanwhile, six peaks at around $3400 \mathrm{~cm}^{-1}, 2850 \mathrm{~cm}^{-1}, 1600 \mathrm{~cm}^{-1}, 1385 \mathrm{~cm}^{-1}, 1050 \mathrm{~cm}^{-1}$, and $900 \mathrm{~cm}^{-1}$ were observed in all of the four types of samples, which may be ascribed to the functional groups introduced by ethylene glycol and sodium acetate during the reaction [26]. A broad stretching band at around $3400 \mathrm{~cm}^{-1}$ represents the stretching vibration of $-\mathrm{OH}$ and $\mathrm{H}-\mathrm{OH}$, probably due to the presence of residual water. The bands at $2850 \mathrm{~cm}^{-1}$ and $1050 \mathrm{~cm}^{-1}$ are assigned to the stretching and bending vibration of $-\mathrm{CH}_{2}$, respectively. The other bands at $1600 \mathrm{~cm}^{-1}, 1385 \mathrm{~cm}^{-1}$, and $900 \mathrm{~cm}^{-1} \mathrm{can}^{-}$ be ascribed to the stretching and bending vibration of $\mathrm{C}=\mathrm{O}, \mathrm{C}-\mathrm{H}$, and $\mathrm{C}-\mathrm{C}$ bonds, respectively [27]. 
The FTIR results show that many oxygen-containing functional groups were present on the surface of the as-prepared materials.
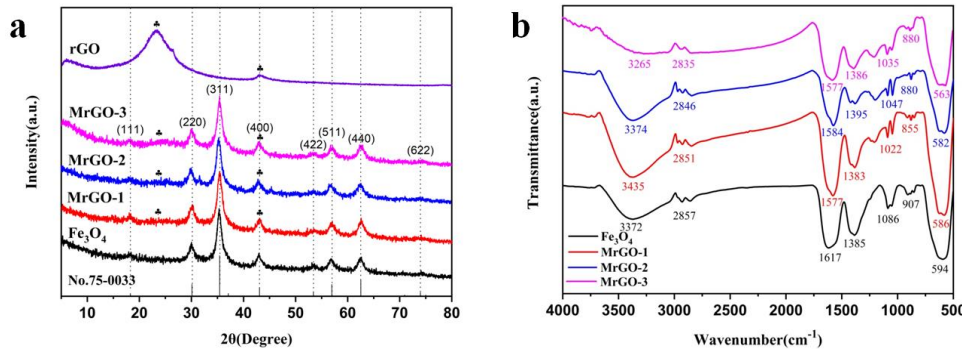

Figure 2. (a) XRD patterns of materials; and (b) FTIR spectra of materials.

The porous properties of the four types of magnetic materials were tested (Figure 3a). The BET-specific surface areas of $\mathrm{Fe}_{3} \mathrm{O}_{4}, \mathrm{MrGO}-1, \mathrm{MrGO}-2$, and MrGO-3 are $15.28 \mathrm{~m}^{2} / \mathrm{g}, 30.08 \mathrm{~m}^{2} / \mathrm{g}$, $47.62 \mathrm{~m}^{2} / \mathrm{g}$, and $38.44 \mathrm{~m}^{2} / \mathrm{g}$, respectively. After incorporating $\mathrm{rGO}$, the specific surface areas of magnetic materials were greater than that of pure $\mathrm{Fe}_{3} \mathrm{O}_{4}$. The pore size distribution of the materials shows that they are mesopore materials. The $\mathrm{Fe}_{3} \mathrm{O}_{4}, \mathrm{MrGO}-1, \mathrm{MrGO}-2$, and $\mathrm{MrGO}-3$ magnetic materials show two scope pore sizes centered at 2-4 $\mathrm{nm}$ and $8-50 \mathrm{~nm}$, respectively. The smaller one may be attributed to the mesopore rGO and the larger one may be resulted from the aggregation and staking of $\mathrm{Fe}_{3} \mathrm{O}_{4}$ [28]. In general, improvement of specific surface areas and abundant pore structures of MrGO are closely related to the adsorption capacity. The average sizes of $\mathrm{Fe}_{3} \mathrm{O}_{4}, \mathrm{MrGO}-1, \mathrm{MrGO}-2$, and MrGO-3 magnetic materials were $55.1 \mathrm{~nm}, 260.9 \mathrm{~nm}, 249.3 \mathrm{~nm}$, and $319.9 \mathrm{~nm}$, respectively (Figure 3b). To investigate the magnetism, the hysteresis loops of the as-prepared materials were recorded at room temperature (Figure 3c). All these samples show ferromagnetic behavior [29]. The corresponding saturation magnetizations $\left(\mathrm{M}_{\mathrm{s}}\right)$ of $\mathrm{Fe}_{3} \mathrm{O}_{4}, \mathrm{MrGO}-1, \mathrm{MrGO}-2$, and $\mathrm{MrGO}-3$ are $51.2 \mathrm{emu} / \mathrm{g}, 38.5 \mathrm{emu} / \mathrm{g}$, $22.7 \mathrm{emu} / \mathrm{g}$, and $14.1 \mathrm{emu} / \mathrm{g}$, respectively. This may be beneficial for chain formation due to the magnetic dipole interaction in the adsorption process. With the increase of rGO content, the saturation magnetization of MrGO nanocomposites decreases gradually.

The thermo gravimetric analysis of MrGO-1, MrGO-2, and MrGO-3 was measured under an air atmosphere to reveal the compositions of MrGO nanocomposites (Figure 3d). The nanocomposites mainly display two stages of weight loss. The first stage of the slight weight loss (about 2-6 wt \%) is ascribed to the evaporation of surface-adsorbed water and solvent molecules under $200{ }^{\circ} \mathrm{C}$. The second stage of the major weight loss is mainly resulted from the decomposition of the rGO skeleton and the removal of the oxygen-containing functional groups at $200-430{ }^{\circ} \mathrm{C}$ [30,31]. The residual mass percentages of the prepared MrGO-1, MrGO-2, and MrGO-3 nanocomposites are about 75.7\%, 62.3\%, and $52.9 \%$, respectively. These values are the weight percentages of $\mathrm{Fe}_{3} \mathrm{O}_{4}$ in the $\mathrm{MrGO}$ nanocomposites.

X-ray photoelectron spectroscopy (XPS) was used to further study the surface chemical composition and electronic structure. The XPS survey results show the presence of $\mathrm{C}, \mathrm{O}$, and Fe elements in MrGO-2 (Figure 4a). The high-resolution XPS spectra of C $1 \mathrm{~s}, \mathrm{O} 1 \mathrm{~s}$, and Fe $2 \mathrm{p}$ were recorded as shown in Figure $4 \mathrm{~b}-\mathrm{d}$. The $\mathrm{C}$ 1s XPS spectrum of the MrGO-2 (Figure $4 \mathrm{~b}$ ) contained three main components including the $\mathrm{C}-\mathrm{C} / \mathrm{C}=\mathrm{C}(284.8 \mathrm{eV}), \mathrm{C}-\mathrm{O}(285.9 \mathrm{eV})$, and $\mathrm{C}=\mathrm{O}(288.8 \mathrm{eV})$ functional groups, which are in great agreement with previously reported work. Additionally, the highest peak value is at $284.8 \mathrm{eV}$, proving that the $\mathrm{sp}^{2}$ bonding of carbon atoms is the main species [32,33]. It can be seen from the spectrum of $\mathrm{O} 1 \mathrm{~s}$ (Figure 4c) that the three peaks at $532.9 \mathrm{eV}, 531.8 \mathrm{eV}$, and $530.3 \mathrm{eV}$ belong to Fe-O, $\mathrm{H}_{2} \mathrm{O}$ molecules, and oxygen-containing groups (-OH and $-\mathrm{COOH}$ ) [34], respectively. In Figure 4d, the Fe $2 \mathrm{p}_{3 / 2}$ and the Fe $2 \mathrm{p}_{1 / 2}$ XPS spectrums demonstrate that the peaks of binding energies are around $711.0 \mathrm{eV}$ and $724.6 \mathrm{eV}$. The satellite peak indicates the characteristic peaks of $\gamma-\mathrm{Fe}_{2} \mathrm{O}_{3}$, which suggests the presence of Fe (III) on the rGO surface [35]. 

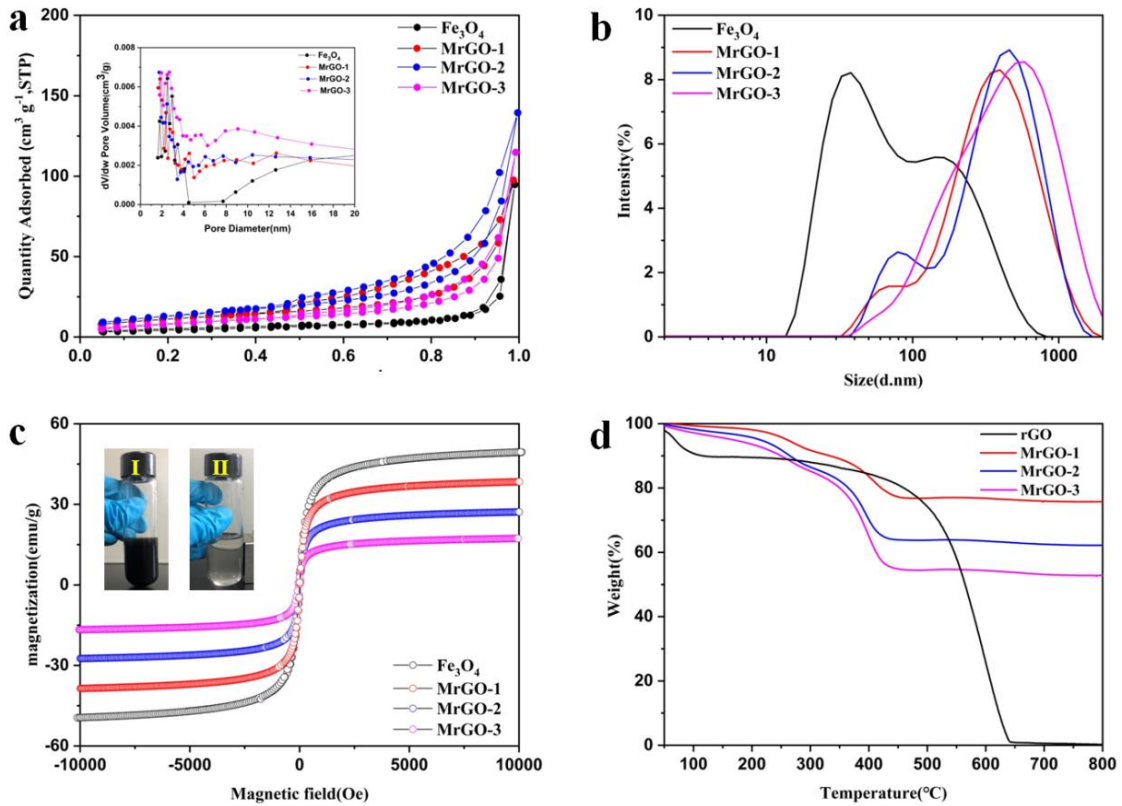

Figure 3. (a) $\mathrm{N}_{2}$ adsorption/desorption isotherms of four types magnetic materials (the inset is BJH pore distribution data); (b) size distribution of four types magnetic materials; (c) the magnetic hysteresis loops of four types magnetic materials (digital image of separation of MrGO-0.2 in water, (I) before and (II) after magnetic separation); (d) TGA curve of magnetic materials.
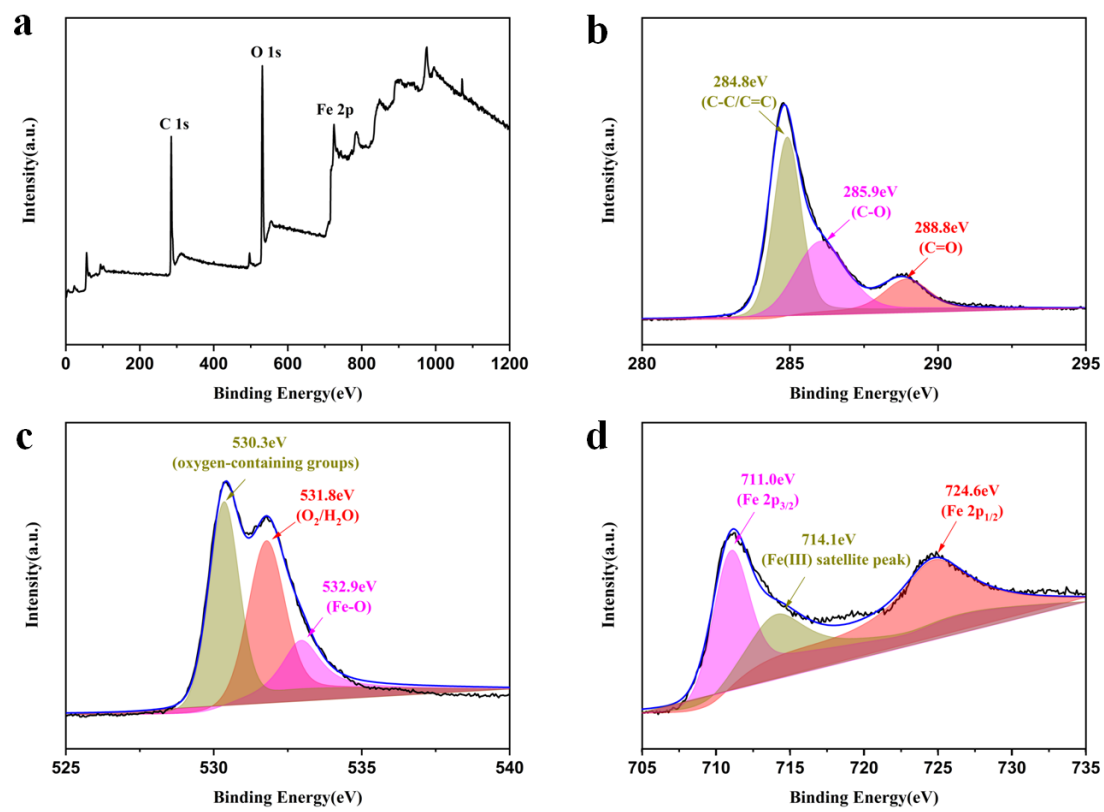

Figure 4. XPS spectra: (a) survey scan, (b) C 1s spectrum, (c) O 1s spectrum, and (d) Fe 2p spectrum of MrGO-2.

To investigate the morphologies and microstructures of magnetic materials, their SEM and TEM images were recorded (Figure 5). It can be observed that the $\mathrm{Fe}_{3} \mathrm{O}_{4}$ exhibits a regular and homogeneous nanoparticle structure (Figure $5 a, b$ ). The diameters of most nanoparticles are less than $100 \mathrm{~nm}$ without obvious agglomeration, which exhibits good crystallinity after reaction. Interestingly, the MrGO-2 presents a wonderful 3D petal-like structure (Figure $5 c, d$ ). This is because the rGO nanosheets were curled and entangled together layer by layer and performed bottom-up electrostatic assembly to form the unique petal-like structure during the reaction. The rGO spread outward so that the $\mathrm{Fe}_{3} \mathrm{O}_{4}$ nanoparticles could anchor onto the petal. On one hand, this rGO nanosheet outside 
could bring large numbers of active sites and target contaminants may be adsorbed from multiple directions, producing $\pi-\pi$ electron donor-acceptors combined with rGO. On the other hand, the $\mathrm{Fe}_{3} \mathrm{O}_{4}$ on the petal could serve as a magnetic core, aggregating contaminants preventing them from desorption. Figure 5e,f displays the TEM images of MrGO-2 in different magnifications. The MrGO-2 is thin and transparent without restacking and agglomeration. Large numbers of $\mathrm{Fe}_{3} \mathrm{O}_{4}$ nanoparticles are uniformly distributed onto the rGO nanosheet and the diameter of the nanoparticle is about 30-50 nm. There seems to be good adhesion between $\mathrm{Fe}_{3} \mathrm{O}_{4}$ and $\mathrm{rGO}$, which may greatly affect the adsorption performance.

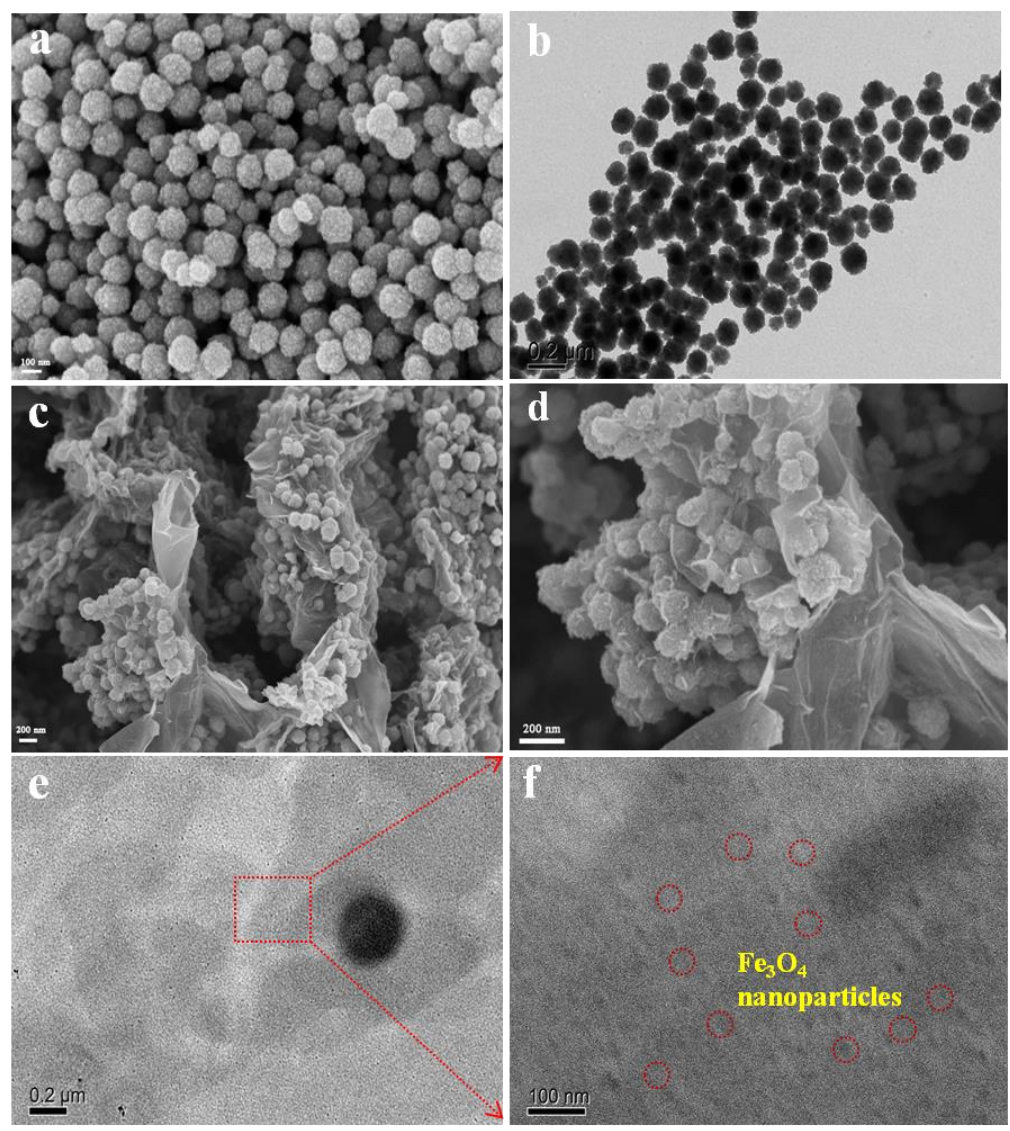

Figure 5. (a) SEM; (b) TEM images of $\mathrm{Fe}_{3} \mathrm{O}_{4}$; (c,d) SEM; (e,f) TEM images of MrGO-2.

\subsection{Adsorption}

The adsorption kinetics of SDZ was investigated to understand the adsorption behavior of different types of magnetic materials (Figure 6a). As the adsorption time increases, the adsorption capacities of MrGO-1, MrGO-2, and MrGO-3 show an obvious increase relative to $\mathrm{Fe}_{3} \mathrm{O}_{4}$. According to the Formulae (1), the adsorption capacities of MrGO-1, MrGO-2, and MrGO-3 were calculated to be $0.90 \mu \mathrm{g} / \mathrm{mg}, 1.36 \mu \mathrm{g} / \mathrm{mg}$, and $1.31 \mu \mathrm{g} / \mathrm{mg}$, respectively after reaction for $24 \mathrm{~h}$, but that of $\mathrm{Fe}_{3} \mathrm{O}_{4}$ was only $0.42 \mu \mathrm{g} / \mathrm{mg}$. This meant that the introduction of rGO into the material can greatly enhance the adsorption capacity. The magnetic materials of MrGO-1, MrGO-2, and MrGO-3 had about 2.14, 3.24, and 3.12 times improvement, respectively. The adsorption capacity of rGO was $1.34 \mu \mathrm{g} / \mathrm{mg}$, which meant that the MrGO-2 and MrGO-3 samples after the magnetizing modification still maintained their adsorption capacity. Furthermore, these data were taken to fit the pseudo-first-order and pseudo-second-order model using Equations (6) and (7) (Figure 6b,c) [36]. According to the correlation coefficient $\left(R^{2}\right)$, the data tends to fit better the pseudo-second-order model than the pseudo-first-order model (Table 2), which indicates that the chemical adsorption of SDZ may exist in the adsorption process [37,38]. This result could be ascribed to the abundant functional groups on the surface of magnetic materials. 
Among these magnetic materials, the MrGO-2 sample had the greatest rate constant for SDZ adsorption $(5.79 \mathrm{mg} /(\mu \mathrm{g} / \mathrm{h}))$. The equilibrium adsorption capacity and the adsorption rate constant results indicate that there were some differences in magnetic materials for removing SDZ. Besides, the adsorption of SDZ on these five adsorbents changed very slowly after $3 \mathrm{~h}$. The kinetic process demonstrates that the adsorption after reaction for $3 \mathrm{~h}$ approaches to equilibrium, which suggests that the reaction time is sufficient to remove SDZ from these adsorbents.
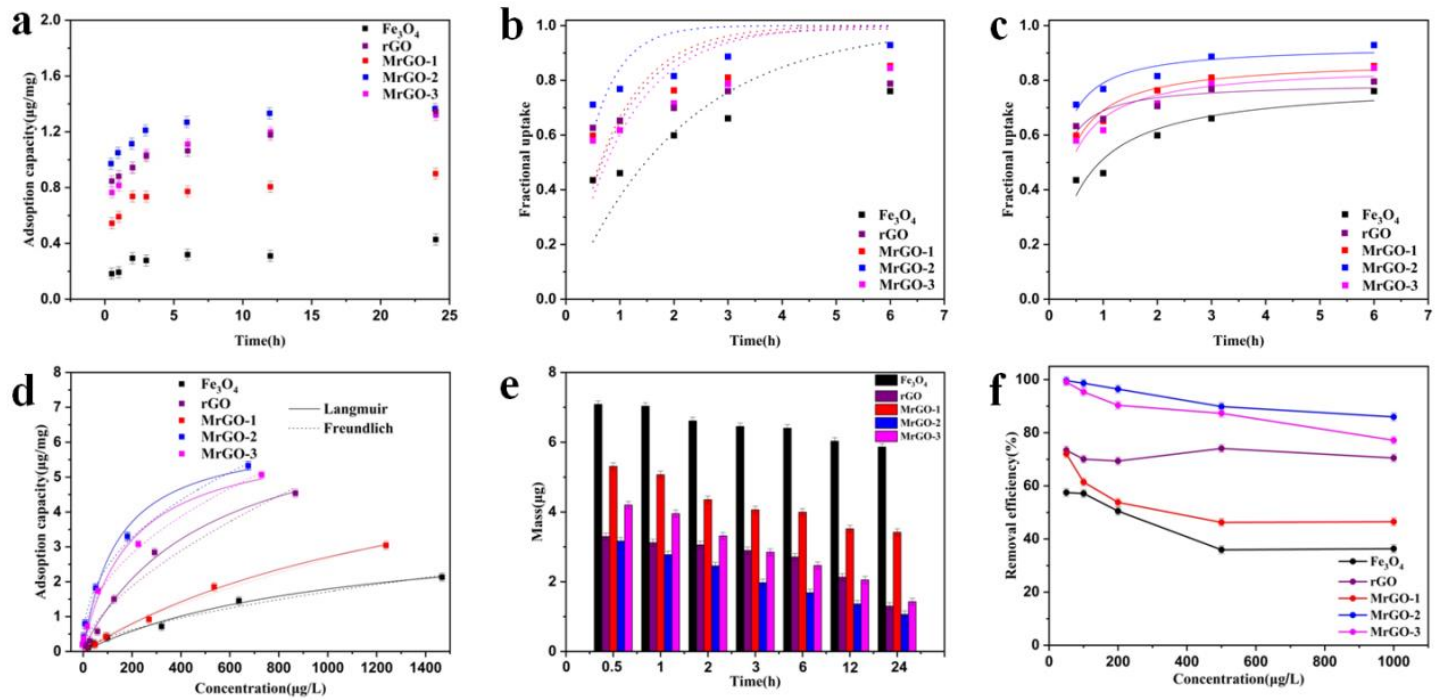

Figure 6. Adsorption behavior of the five types of magnetic materials: (a) adsorption kinetics, (b) pseudo-first-order fit for $t \leq 6 \mathrm{~h}$, (c) pseudo-second-order fit for $t \leq 6 \mathrm{~h}$, (d) adsorption isotherms, (e) SDZ mass variation, (f) SDZ removal efficiency. Reaction conditions: $\mathrm{T}_{0}=25{ }^{\circ} \mathrm{C}$, $\mathrm{C}_{0, \mathrm{SDZ}}=(\mathbf{a}, \mathbf{c})=400 \mu \mathrm{g} / \mathrm{L}, \mathrm{C}_{0, \mathrm{SDZ}}=(\mathbf{b}, \mathbf{d})=50-2000 \mu \mathrm{g} / \mathrm{L}$, (adsorbents) $=0.25 \mathrm{~g} / \mathrm{L}$ and $\mathrm{pH}$ with no adjustment.

Table 2. Relevant parameters of the adsorption experiments.

\begin{tabular}{|c|c|c|c|c|c|c|c|c|c|c|c|c|}
\hline \multirow[b]{2}{*}{ Samples } & \multicolumn{3}{|c|}{ Pseudo-First-Order } & \multicolumn{3}{|c|}{ Pseudo-Second-Order } & \multicolumn{3}{|c|}{ Langmuir } & \multicolumn{3}{|c|}{ Freundlich } \\
\hline & $\begin{array}{c}\mathrm{k}_{1} \\
\left(\mathrm{~h}^{-1}\right)\end{array}$ & $\begin{array}{c}Q_{e} \\
(\mu \mathrm{g} / \mathrm{mg})\end{array}$ & $\mathbf{R}^{2}$ & $\begin{array}{c}\mathbf{k}_{2} \\
(\mathrm{mg} /(\mu \mathrm{g} \cdot \mathrm{h})\end{array}$ & $\begin{array}{c}Q_{e} \\
(\mu \mathrm{g} / \mathrm{mg})\end{array}$ & $\mathbf{R}^{2}$ & $\begin{array}{c}\mathrm{K}_{\mathrm{L}} \\
(\mathrm{L} / \mu \mathrm{g})\end{array}$ & $\underset{(\mu \mathrm{g} / \mathrm{mg})}{\mathrm{Q}_{\mathrm{m}}}$ & $\mathbf{R}^{2}$ & $\begin{array}{c}\mathrm{K}_{\mathrm{F}} \\
\left(\mu \mathrm{g} / \mathrm{mg}(\mathrm{L} / \mu \mathrm{g})^{1 / n}\right)\end{array}$ & $\mathbf{n}$ & $\mathbf{R}^{2}$ \\
\hline $\mathrm{Fe}_{3} \mathrm{O}_{4}$ & 0.47 & 0.42 & 0.333 & 1.83 & 0.37 & 0897 & $9.51 \times 10^{-4}$ & 3.67 & 0.987 & 0.022 & 1.59 & 0.986 \\
\hline $\mathrm{rGO}$ & 1.05 & 1.33 & 0.695 & 5.67 & 1.16 & 0.839 & $1.96 \times 10^{-3}$ & 7.24 & 0.993 & 0.062 & 1.57 & 0.969 \\
\hline MrGO-1 & 1.09 & 0.90 & 0.783 & 3.73 & 1.40 & 0.942 & $6.71 \times 10^{-4}$ & 4.74 & 0.996 & 0.017 & 1.37 & 0.992 \\
\hline MrGO-2 & 1.86 & 1.36 & 0.731 & 5.79 & 1.55 & 0.893 & $7.21 \times 10^{-3}$ & 6.27 & 0.987 & 0.36 & 2.41 & 0.967 \\
\hline MrGO-3 & 0.92 & 1.31 & 0.733 & 3.44 & 1.49 & 0.890 & $5.16 \times 10^{-3}$ & 6.26 & 0.985 & 0.23 & 2.13 & 0.974 \\
\hline
\end{tabular}

$\mathrm{k}_{1}$ : the pseudo-first-order adsorption rate constant; $\mathrm{k}_{2}$ : the pseudo-second-order adsorption rate constant; $\mathrm{K}_{\mathrm{L}}$ : the Langmuir isotherm constant; $\mathrm{K}_{\mathrm{F}}$ : the Freundlich isotherm constant; $\mathrm{n}$ : the measure of adsorption intensity; $\mathrm{Q}_{\mathrm{e}}$ : the adsorption capacity at the equilibrium state (measure); $\mathrm{Q}_{\mathrm{m}}$ : the maximum adsorption capacity (calculate).

The adsorption isotherms of SDZ for the five adsorbents were measured (Figure 6d). These materials showed an obvious increase in the adsorption capacity, with the increase of the initial concentration of SDZ. At the initial concentration of $2000 \mu \mathrm{g} / \mathrm{L}$, the adsorption capacities of $\mathrm{Fe}_{3} \mathrm{O}_{4}, \mathrm{rGO}, \mathrm{MrGO}-1, \mathrm{MrGO}-2$, and MrGO-3 were $2.13 \mu \mathrm{g} / \mathrm{mg}, 4.51 \mu \mathrm{g} / \mathrm{mg}, 3.05 \mu \mathrm{g} / \mathrm{mg}, 5.31 \mu \mathrm{g} / \mathrm{mg}$, and $5.07 \mu \mathrm{g} / \mathrm{mg}$, respectively, in the adsorption equilibrium state. Both Langmuir and Freundlich models were used to study the adsorption $[39,40]$. The materials exhibited a better correlation with the Langmuir adsorption model than that of the Freundlich model (Table 2). Using the Langmuir model, the maximum adsorption capacities of MrGO-1, MrGO-2, and MrGO-3 were calculated to be $6.74 \mu \mathrm{g} / \mathrm{mg}, 6.27 \mu \mathrm{g} / \mathrm{mg}$, and $6.26 \mu \mathrm{g} / \mathrm{mg}$, respectively, which was an improvement on that of $\mathrm{Fe}_{3} \mathrm{O}_{4}$ $(3.67 \mu \mathrm{g} / \mathrm{mg})$. The isotherm constants of the adsorbents were consistent with the adsorption kinetics result. The MrGO-2 sample was the most efficient of the five types of materials. 
The SDZ mass variation of these adsorbents were investigated in the adsorption process (Figure 6e). The total mass of SDZ in the aqueous solution was $8 \mu \mathrm{g}$. In the presence of MrGO-2, the mass of SDZ decreased rapidly within $0.5 \mathrm{~h}$, and further decreased to $1.06 \mu \mathrm{g}$ after $24 \mathrm{~h}$. In the case of $\mathrm{Fe}_{3} \mathrm{O}_{4}$, the mass did not decrease significantly and still remained at $5.86 \mu \mathrm{g}$ after reaction for $24 \mathrm{~h}$. The mass of MrGO- 1 and MrGO-3 were $3.52 \mu \mathrm{g}$ and $1.42 \mu \mathrm{g}$, respectively, indicating the better adsorption capacity of these two adsorbents than pure $\mathrm{Fe}_{3} \mathrm{O}_{4}$. In other words, $\mathrm{rGO}$ played an important role influencing the adsorption performance of the magnetic materials.

The removal of SDZ with different initial concentrations was shown in Figure 6f. MrGO-2 exhibited the highest removal efficiency among the five types of materials. The removal efficiencies of SDZ by $\mathrm{Fe}_{3} \mathrm{O}_{4}, \mathrm{rGO}$, MrGO-1, MrGO-2, and MrGO-3 were 57.6\%, 73.4\%, 72.1\%, 99.6\%, and 99.1\%, respectively, at the initial concentration of $50 \mu \mathrm{g} / \mathrm{L}$. When the concentration of SDZ was increased to $1000 \mu \mathrm{g} / \mathrm{L}$, the removal efficiencies of SDZ by these five materials changed to $36.3 \%, 70.5 \%, 46.5 \%, 85.9 \%$, and $77.1 \%$, respectively. The pure $\mathrm{Fe}_{3} \mathrm{O}_{4}$ sample showed the lowest removal efficiency toward both low and high concentrations of SDZ. First, this phenomenon may be due to the serious agglomeration of magnetic $\mathrm{Fe}_{3} \mathrm{O}_{4}$. Second, an appropriate content of $\mathrm{rGO}$ brought functional groups, and these groups could serve as the active sites for improving the absorption capacity of the materials. Third, target contaminants were prone to desorption without magnetism. Comparing the results presented above, it can be concluded that MrGO-2 is the most reactive material for SDZ removal.

\subsection{Recyclability}

The recyclability of adsorbent is a vital factor for evaluating its practical applications in the environment. Therefore, the recyclability of MrGO-2 was further investigated and the results are shown in Figure 7. After five repeated adsorption cycles, the removal efficiency still remained at $89.3 \%$. Compared to the first adsorption, the removal efficiency showed only about a 3\% decrease after five cycles. This result suggests that the adsorbent has remarkable recyclability and it has the potential for removing SDZ from aqueous solutions.

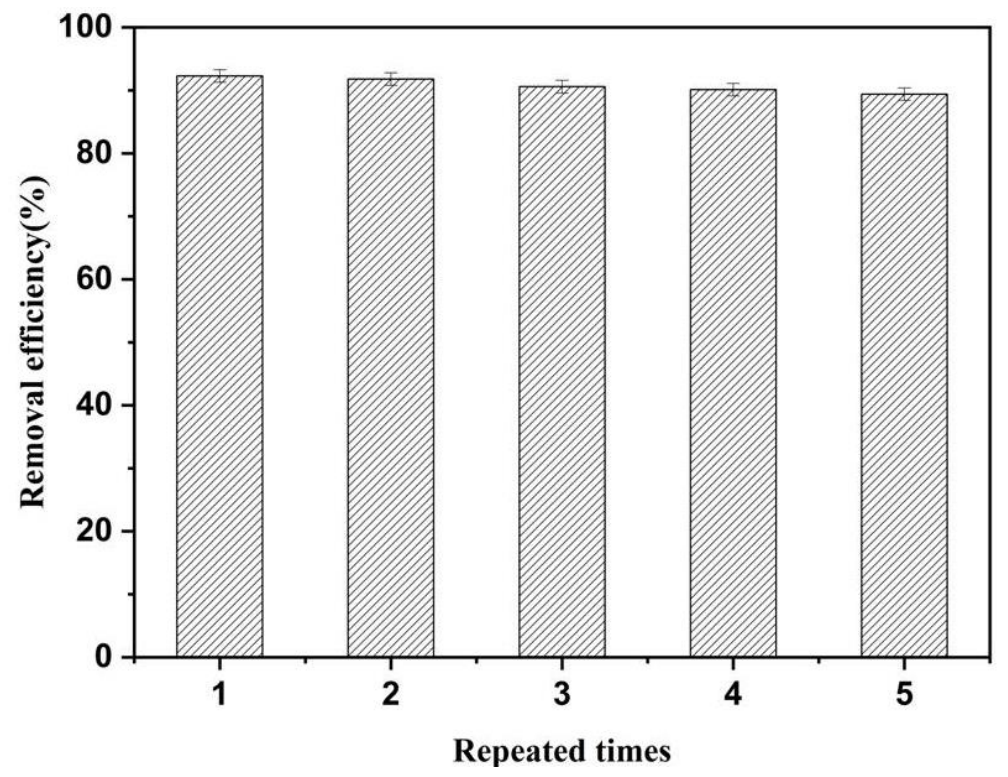

Figure 7. Recyclability of MrGO-2. Reaction conditions: $\mathrm{T}_{0}=25^{\circ} \mathrm{C}, \mathrm{C}_{0}, \mathrm{SDZ}=100 \mu \mathrm{g} / \mathrm{L},(\mathrm{MrGO}-2)=0.25 \mathrm{~g} / \mathrm{L}$ and $\mathrm{pH}$ with no adjustment.

\subsection{Applications}

To demonstrate the application capability of MrGO-2 in real water environments, batch adsorption experiments were conducted to investigate the influence of various parameters including solution 
$\mathrm{pH}(3-11)$, natural organic matters $(0-2000 \mu \mathrm{g} / \mathrm{L}$ as humic acid (HA)), ion strength $(0-2000 \mu \mathrm{g} / \mathrm{L}$ as $\mathrm{NaCl})$, common co-existing cations/anions $(1000 \mu \mathrm{g} / \mathrm{L})$, and the three real water samples collected. The adsorption experiments in real water detail were conducted using the same procedures specified at the experimental section. The initial spiked concentration of SDZ was $100 \mu \mathrm{g} / \mathrm{L}$ and the solutions were placed on a rotating shaker with a speed of $180 \mathrm{rpm}$ for $3 \mathrm{~h}$. The results of adsorption were displayed in Figure 8. The $\mathrm{pH}$ value was a vital parameter that affects most solid-liquid systems. The removal of SDZ under different $\mathrm{pH}$ values showed that a better result was achieved under acidic conditions (Figure 8a). This is probably because the adsorbent with oxygen-containing functional groups possesses faint acidity, which makes it easy for the target contaminant to approach in the adsorption process. When the initial $\mathrm{pH}$ value of the solution was increased to 11, the removal of SDZ decreased slightly. Humic acid is a common natural organic matter in water and wastewater. With the increase of HA concentrations from 0 to $1000 \mu \mathrm{g} / \mathrm{L}$, the removal efficiency of SDZ declined from $91.3 \%$ to $72.2 \%$ (Figure $8 \mathrm{~b}$ ). This decline may be resulted from the strong competition from HA, which could be adsorbed onto the surface of MrGO-2 via $\pi-\pi$ interactions. The effect of ionic strength on the removal of SDZ by MrGO-2 was investigated with $\mathrm{NaCl}$ as the auxiliary electrolyte (Figure $8 \mathrm{c}$ ). The removal of SDZ increased when, $\mathrm{NaCl}$ with concentrations in the range of 0 to $200 \mu \mathrm{g} / \mathrm{L}$, was added. It is generally believed that an appropriate electrolyte can improve the electric double layer surface and weaken the electrostatic repulsion between SDZ and MrGO-2. Various common co-existing cations and anions $\left(\mathrm{Fe}^{2+}, \mathrm{Cu}^{2+}, \mathrm{Mn}^{2+}, \mathrm{Cl}^{-}, \mathrm{NO}_{3}{ }^{-}\right.$, and $\left.\mathrm{SO}_{4}{ }^{2-}\right)$ were observed to affect the removal of SDZ by MrGO-2 (Figure $8 \mathrm{~d}, \mathrm{e}$ ). The removal rate of SDZ was $91.3 \%$ without the presence of cations. After the addition of $\mathrm{Fe}^{2+}, \mathrm{Cu}^{2+}$, and $\mathrm{Mn}^{2+}$, the removal of SDZ decreased to $89.6 \%, 87.3 \%$, and $84.2 \%$, respectively. This may be because these cations have certain affinities for the adsorption sites of MrGO-2. The co-existing anions added had no significant effect on the removal of SDZ. The effectiveness of MrGO-2 was further evaluated using three different real water samples (Figure 8f). It showed that the removal rates of SDZ in SW, RW, and WW were $54.6 \%, 55.9 \%$, and $48.8 \%$, respectively. The comparatively ordinary removal efficiencies with these real waters could be probably ascribed to the presence of relatively high concentrations of dissolved organic compounds $(2.3 \mathrm{mg} / \mathrm{L}$ in $\mathrm{LW}, 2.5 \mathrm{mg} / \mathrm{L}$ in $\mathrm{RW}$, and $6.7 \mathrm{mg} / \mathrm{L}$ in WW). Besides, the co-existing cations/anions and the ionic strength in real waters could also affect the removal efficiency.
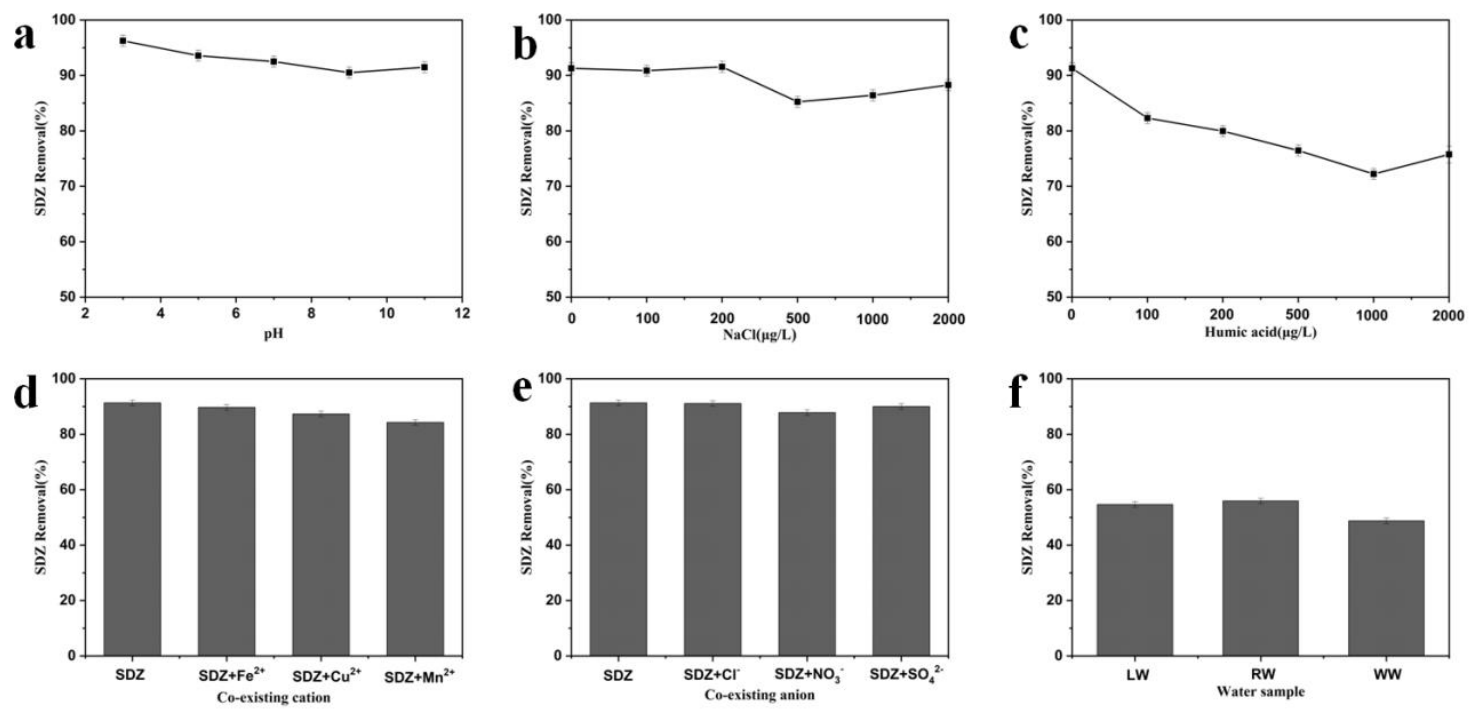

Figure 8. Effects of various water parameters and components on the removal of SDZ by MrGO-2: (a) $\mathrm{pH},(\mathbf{b})$ natural organic matter, (c) ionic strength, (d) co-existing cation, (e) co-existing anion, (f) three real waters. Reaction conditions: $\mathrm{T}_{0}=25^{\circ} \mathrm{C}, \mathrm{C}_{0}, \mathrm{SDZ}=100 \mu \mathrm{g} / \mathrm{L}$, (adsorbents) $=0.25 \mathrm{~g} / \mathrm{L}$ and $\mathrm{pH}$ with no adjustment. 


\section{Conclusions}

The MrGO nanocomposites were synthesized via a modified solvothermal method. Different graphene-based magnetic nanocomposites were employed to remove SDZ from water. The adsorption capacity of MrGO-2 showed approximately 3.24 times that of pure $\mathrm{Fe}_{3} \mathrm{O}_{4}$. After five repeated adsorption cycles, the removal rate of SDZ by MrGO- 2 still remained at $89.3 \%$, which was only about a 3\% decrease compared to that in the first cycle. This excellent adsorption performance and recyclability of $\mathrm{MrGO}$ could be attributed to the wonderful 3D interconnected petal-like structure. With the assistance of material characterization and balance analysis, the removal of SDZ was found to be mediated probably by both chemical and physical adsorption. The relative contents of rGO and $\mathrm{Fe}_{3} \mathrm{O}_{4}$ seem to play an important role in the construction of their 3D structures and adsorption performance. The MrGO after the adsorption experiments can be easily recycled via magnetic separation. Moreover, the MrGO-2 also exhibited excellent adsorption performance in real water environments. The initial concentration of SDZ was at trace levels, which was close to the concentration in the actual environments. This work proposes a novel material with unique 3D-interconnected structures for promoting the adsorption capacity, which has certain application prospects in practical water treatment.

Author Contributions: J.Z.: Conceptualization, Investigation, Methodology, Visualization, Data curation, Writing—original draft preparation; Y.F.: Methodology, Analysis, Writing—review and editing; J.-L.L.: Analysis; B.Y.: Resources; G.-G.Y.: Resources, Supervision, Writing-review and editing. All authors have read and agreed to the published version of the manuscript.

Funding: This study was financially supported by the Key R \& D program of Guangxi Province, China (2018AB36018), and the National Natural Science Foundation of China (NSFC U1701242).

Conflicts of Interest: The authors declare no conflict of interest or competing financial relationships.

\section{References}

1. Le Page, G.; Gunnarsson, L.; Snape, J.; Tyler, C.R. Integrating human and environmental health in antibiotic risk assessment: A critical analysis of protection goals, species sensitivity and antimicrobial resistance. Environ. Int. 2017, 109, 155-169. [CrossRef]

2. Qiao, M.; Ying, G.-G.; Singer, A.C.; Zhu, Y.-G. Review of antibiotic resistance in China and its environment. Environ. Int. 2018, 110, 160-172. [CrossRef] [PubMed]

3. Zhang, Q.-Q.; Ying, G.-G.; Pan, C.-G.; Liu, Y.-S.; Zhao, J.-L. Comprehensive evaluation of antibiotics emission and fate in the river basins of china: Source analysis, multimedia modeling, and linkage to bacterial resistance. Environ. Sci. Technol. 2015, 49, 6772-6782. [CrossRef] [PubMed]

4. Xu, W.; Zhang, G.; Li, X.-D.; Zou, S.; Li, P.; Hu, Z.; Li, J. Occurrence and elimination of antibiotics at four sewage treatment plants in the Pearl River Delta (PRD), South China. Water Res. 2007, 41, 4526-4534. [CrossRef] [PubMed]

5. Chang, X.; Meyer, M.T.; Liu, X.; Zhao, Q.; Chen, H.; Chen, J.-A.; Qiu, Z.; Yang, L.; Cao, J.; Shu, W. Determination of antibiotics in sewage from hospitals, nursery and slaughter house, wastewater treatment plant and source water in Chongqing region of Three Gorge Reservoir in China. Environ. Pollut. 2010, 158, 1444-1450. [CrossRef] [PubMed]

6. García-Galán, M.J.; Garrido, T.; Fraile, J.; Ginebreda, A.; Díaz-Cruz, M.S.; Barceló, J.; Ginebreda, A. Simultaneous occurrence of nitrates and sulfonamide antibiotics in two ground water bodies of Catalonia (Spain). J. Hydrol. 2010, 383, 93-101. [CrossRef]

7. Wang, N.; Guo, X.; Xu, J.; Kong, X.; Gao, S.; Shan, Z. Pollution characteristics and environmental risk assessment of typical veterinary antibiotics in livestock farms in Southeastern China. J. Environ. Sci. Health Part B 2014, 49, 468-479. [CrossRef]

8. Ahmed, M.B.; Zhou, J.L.; Ngo, H.H.; Guo, W.; Johir, A.H.; Belhaj, D. Competitive sorption affinity of sulfonamides and chloramphenicol antibiotics toward functionalized biochar for water and wastewater treatment. Bioresour. Technol. 2017, 238, 306-312. [CrossRef]

9. Gao, Y.; Li, Y.; Zhang, L.; Huang, H.; Hu, J.; Shah, S.M.; Su, X. Adsorption and removal of tetracycline antibiotics from aqueous solution by graphene oxide. J. Colloid Interface Sci. 2012, 368, 540-546. [CrossRef] 
10. Fan, J.; Yu, C.; Gao, F.; Lei, J.; Tian, B.; Wang, L.; Luo, Q.; Tu, B.; Zhou, W.; Zhao, D. Cubic mesoporous silica with large controllable entrance sizes and advanced adsorption properties. Angew. Chem. Int. Ed. 2003, 42, 3146-3150. [CrossRef]

11. Zhang, Y.; Yue, Q.; Yu, L.; Yang, X.; Hou, X.; Zhao, D.; Cheng, X.; Deng, Y. Amphiphilic block copolymers directed interface coassembly to construct multifunctional microspheres with magnetic core and monolayer mesoporous aluminosilicate shell. Adv. Mater. 2018, 30, e1800345. [CrossRef] [PubMed]

12. Shan, D.; Deng, S.; Li, J.; Wang, H.; He, C.; Cagnetta, G.; Wang, B.; Wang, Y.; Huang, J.; Yu, G. Preparation of porous graphene oxide by chemically intercalating a rigid molecule for enhanced removal of typical pharmaceuticals. Carbon 2017, 119, 101-109. [CrossRef]

13. Zhang, X.; Shen, J.; Zhuo, N.; Tian, Z.; Xu, P.; Yang, Z.; Yang, W. Interactions between antibiotics and graphene-based materials in water: A Comparative experimental and theoretical investigation. ACS Appl. Mater. Interfaces 2016, 8, 24273-24280. [CrossRef] [PubMed]

14. Fan, L.; Luo, C.; Li, X.; Lu, F.; Qiu, H.; Sun, M. Fabrication of novel magnetic chitosan grafted with graphene oxide to enhance adsorption properties for methyl blue. J. Hazard. Mater. 2012, 215, 272-279. [CrossRef] [PubMed]

15. Gui, C.-X.; Wang, Q.-Q.; Hao, S.-M.; Qu, J.; Huang, P.-P.; Cao, C.; Song, W.; Yu, Z.-Z. Sandwichlike magnesium silicate/reduced graphene oxide nanocomposite for enhanced $\mathrm{Pb}^{2+}$ and methylene blue adsorption. ACS Appl. Mater. Interfaces 2014, 6, 14653-14659. [CrossRef]

16. Ji, L.; Wan, Y.; Zheng, S.; Zhu, D. Adsorption of tetracycline and sulfamethoxazole on crop residue-derived ashes: Implication for the relative importance of black carbon to soil sorption. Environ. Sci. Technol. 2011, 45, 5580-5586. [CrossRef]

17. Zuo, L.; Ai, J.; Fu, H.; Chen, W.; Zheng, S.; Xu, Z.; Zhu, D. Enhanced removal of sulfonamide antibiotics by $\mathrm{KOH}$-activated anthracite coal: Batch and fixed-bed studies. Environ. Pollut. 2016, 211, 425-434. [CrossRef]

18. Li, H.; Zou, L.; Pan, L.; Sun, Z. Novel graphene-like electrodes for capacitive deionization. Environ. Sci. Technol. 2010, 44, 8692-8697. [CrossRef]

19. Nasiri, R.; Arsalani, N.; Panahian, Y. One-pot synthesis of novel magnetic three-dimensional graphene/chitosan/nickel ferrite nanocomposite for lead ions removal from aqueous solution: RSM modelling design. J. Clean. Prod. 2018, 201, 507-515. [CrossRef]

20. Sha, J.; Li, Y.; Salvatierra, R.V.; Wang, T.; Dong, P.; Ji, Y.; Lee, S.-K.; Zhang, C.; Zhang, J.; Smith, R.H.; et al. Three-dimensional printed graphene foams. ACS Nano 2017, 11, 6860-6867. [CrossRef]

21. He, F.; Fan, J.T.; Ma, N.; Zhang, L.; Leung, C.; Chan, H.L.; Leung, C.W. The attachment of $\mathrm{Fe}_{3} \mathrm{O}_{4}$ nanoparticles to graphene oxide by covalent bonding. Carbon 2010, 48, 3139-3144. [CrossRef]

22. Yang, Z.; Yan, H.; Yang, H.; Li, H.; Li, A.-M.; Cheng, R. Flocculation performance and mechanism of graphene oxide for removal of various contaminants from water. Water Res. 2013, 47, 3037-3046. [CrossRef]

23. Zhong, J.; Yi, F.; Gao, A.; Shu, D.; Huang, Y.; Li, Z.; Zhu, W.; He, C.; Meng, T.; Zhao, S. Preparation of $3 \mathrm{D}$ reduced graphene Oxide/ $\mathrm{MnO}_{2}$ nanocomposites through a vacuum-impregnation method and their electrochemical capacitive behavior. ChemElectroChem 2017, 4, 1088-1094. [CrossRef]

24. Touqeer, T.; Mumtaz, M.W.; Mukhtar, H.; Irfan, A.; Akram, S.; Shabbir, A.; Rashid, U.; Nehdi, I.; Yaw, T.C.S. $\mathrm{Fe}_{3} \mathrm{O}_{4}$-PDA-Lipase as surface functionalized nano biocatalyst for the production of biodiesel using waste cooking oil as feedstock: Characterization and process optimization. Energies 2019, 13, 177. [CrossRef]

25. Ni, H.; Sun, X.; Li, Y.; Li, C. Solvothermal self-assembly of magnetic $\mathrm{Fe}_{3} \mathrm{O}_{4}$ nanochains by ethylenediamine functionalized nanoparticles for chromium (VI) removal. J. Mater. Sci. 2015, 50, 4270-4279. [CrossRef]

26. Zheng, J.-G.; Zhang, Y.; Zhai, Y.; Yang, H. TEM and EBSD study of $\mathrm{Fe}_{3} \mathrm{O}_{4}$ particle chains grown and assembled in external magnetic field. Microsc. Microanal. 2010, 16, 1790-1791. [CrossRef]

27. Bastami, T.R.; Entezari, M.; Hu, Q.H.; Hartono, S.B.; Qiao, S. Role of polymeric surfactants on the growth of manganese ferrite nanoparticles. Chem. Eng. J. 2012, 210, 157-165. [CrossRef]

28. Lian, C.; Wang, Z.; Lin, R.; Wang, D.; Chen, C.; Li, Y. An efficientfficient, controllable and facile two-step synthesis strategy: $\mathrm{Fe}_{3} \mathrm{O}_{4} @ \mathrm{RGO}$ composites with various $\mathrm{Fe}_{3} \mathrm{O}_{4}$ nanoparticles and their supercapacitance properties. Nano Res. 2017, 10, 3303-3313. [CrossRef]

29. Liu, Y.; Wang, Y.; Zhou, S.; Lou, S.; Yuan, L.; Gao, T.; Wu, X.; Shi, X.; Wang, K. Synthesis of high saturation magnetization superparamagnetic $\mathrm{Fe}_{3} \mathrm{O}_{4}$ hollow microspheres for swift chromium removal. ACS Appl. Mater. Interfaces 2012, 4, 4913-4920. [CrossRef] [PubMed]

30. Oulego, P.; Laca, A.; Calvo, S.; Díaz, M. Eggshell-supported catalysts for the advanced oxidation treatment of humic acid polluted wastewaters. Water 2019, 12, 100. [CrossRef] 
31. Ren, B.; Shen, W.; Li, L.; Wu, S.; Wang, W. 3D CoFe $\mathrm{O}_{4}$ nanorod/flower-like $\mathrm{MoS}_{2}$ nanosheet heterojunctions as recyclable visible light-driven photocatalysts for the degradation of organic dyes. Appl. Surf. Sci. 2018, 447, 711-723. [CrossRef]

32. Huang, Y.; Zhang, W.; Ruan, G.; Li, X.; Cong, Y.; Du, F.; Li, J. Reduced graphene oxide-hybridized polymeric high-internal phase emulsions for highly efficient removal of polycyclic aromatic hydrocarbons from water matrix. Langmuir 2018, 34, 3661-3668. [CrossRef] [PubMed]

33. Zhang, N.; Huang, Y.; Zong, M.; Ding, X.; Li, S.; Wang, M. Synthesis of ZnS quantum dots and $\mathrm{CoFe}_{2} \mathrm{O}_{4}$ nanoparticles co-loaded with graphene nanosheets as an efficient broad band EM wave absorber. Chem. Eng. J. 2017, 308, 214-221. [CrossRef]

34. Zhang, S.-H.; Wu, M.-F.; Tang, T.; Xing, Q.-J.; Peng, C.-Q.; Li, F.; Liu, H.; Luo, X.-B.; Zou, J.-P.; Min, X.-B.; et al. Mechanism investigation of anoxic $\mathrm{Cr}(\mathrm{VI})$ removal by nano zero-valent iron based on XPS analysis in time scale. Chem. Eng. J. 2018, 335, 945-953. [CrossRef]

35. Su, S.; Liu, Y.; He, W.; Tang, X.; Jin, W.; Zhao, Y. A novel graphene oxide-carbon nanotubes anchored $\alpha$-FeOOH hybrid activated persulfate system for enhanced degradation of Orange II. J. Environ. Sci. 2019, 83, 73-84. [CrossRef]

36. Simonin, J.-P. On the comparison of pseudo-first order and pseudo-second order rate laws in the modeling of adsorption kinetics. Chem. Eng. J. 2016, 300, 254-263. [CrossRef]

37. Han, J.; Zhang, G.; Zhou, L.; Zhan, F.; Cai, D.; Wu, Z. Waste carton-derived nanocomposites for efficient removal of hexavalent chromium. Langmuir 2018, 34, 5955-5963. [CrossRef]

38. Yi, Y.; Tu, G.; Zhao, D.; Tsang, P.E.; Fang, Z. Biomass waste components significantly influence the removal of $\mathrm{Cr}(\mathrm{VI})$ using magnetic biochar derived from four types of feedstocks and steel pickling waste liquor. Chem. Eng. J. 2019, 360, 212-220. [CrossRef]

39. Luo, L.; Xu, C.; Chen, Z.; Zhang, S. Properties of biomass-derived biochars: Combined effects of operating conditions and biomass types. Bioresour. Technol. 2015, 192, 83-89. [CrossRef]

40. Mohan, D.; Kumar, A.; Sarswat, A.; Franco, M.A.; Pittman, C.U. Cadmium and lead remediation using magnetic oak wood and oak bark fast pyrolysis bio-chars. Chem. Eng. J. 2014, 236, 513-528. [CrossRef]

(C) 2020 by the authors. Licensee MDPI, Basel, Switzerland. This article is an open access article distributed under the terms and conditions of the Creative Commons Attribution (CC BY) license (http://creativecommons.org/licenses/by/4.0/). 